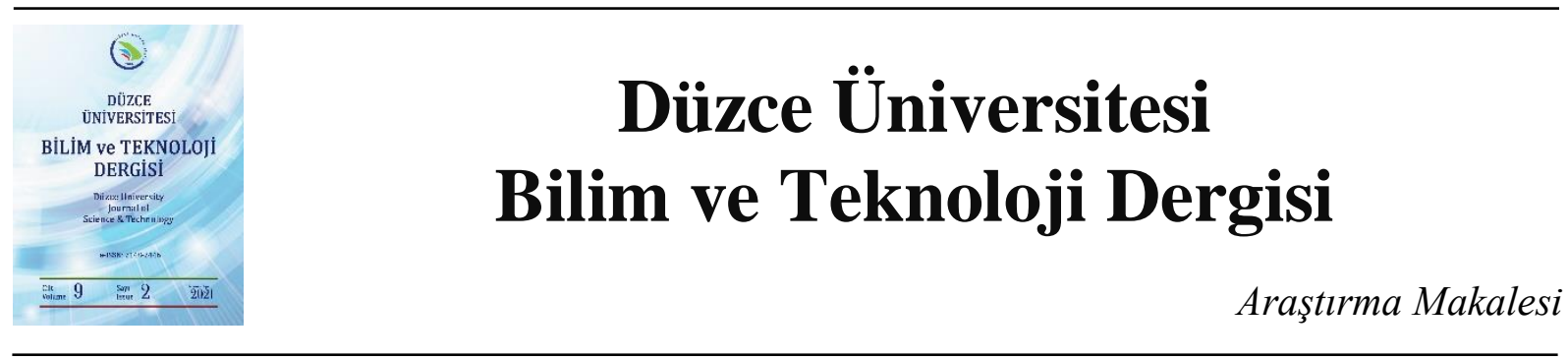

\section{TIG Kaynak Yöntemi ile Birleştirilen Ti6A14V Titanyum Alaşımının Mikroyap1, Sertlik ve Asidik Ortamdaki Korozyon Özelliklerinin İncelenmesi}

\author{
Kubilay KARACIF ${ }^{\text {a,* }}$ \\ ${ }^{a}$ Metalurji ve Malzeme Mühendisliği Bölümü, Mühendislik Fakültesi, Hitit Üniversitesi, Çorum, TÜRKIYY \\ * Sorumlu yazarın e-posta adresi: kubilaykaracif@ hitit.edu.tr
}

DOI: 10.29130/dubited.799862

\begin{abstract}
ÖZET
Titanyum alaşımları, üstün özellikleri nedeni ile birçok alanda kullanılmaktadır. Bu alaşımlardan yapılan imalat işlemlerinde veya sonrasında kaynak ile birleştirme yapılmaktadır. Bu çalışmada kaynak ile birleştirilen Ti6Al4V titanyum alaşımının mikroyapı, sertlik ve asidik ortamdaki korozyon özellikleri incelenmiştir. Asidik ortamdaki korozyon özelliğinin incelenmesinin amacı, kaynaklı titanyum alaşımlarından yapılan imalatların kimya, petrokimya ve benzeri alanlarda asidik ortamlarda kullanılmasıdır. Ti6Al4V titanyum alaşımının kullanıldığı çalışmada Tungsten İnert Gaz (TIG) kaynak yöntemi ile birleştirme yapılmıştır. Optik mikroskop ile mikroyapılar incelenmiş, Vickers yöntemi ile sertlik testleri yapılmıştır. Asidik ortamdaki korozyon davranışının belirlenmesinde potansiyodinamik yöntem ile elektrokimyasal korozyon deneyleri uygulanmıştır. Mikroyapı sonuçlarına göre TIG kaynağı ile Ti6Al4V titanyum alaşımı parçalarda iyi bir birleşmenin gerçekleştiği, kaynak metalinin hem ince uzun morfolojide asiküler $\alpha$ fazı hem de büyük boyutlu $\beta$ fazı tanelerinden oluştuğu görülmüsşür. Isı tesiri altındaki kaynak bölgesinde kaynak metaline yaklaşıldıkça sertlik artmıştır. Kaynak metali sertliği de esas metale göre oldukça yüksektir. TIG kaynaklı titanyum alaşımının asidik ortamdaki korozyon hızı kaynaksız titanyum alaşımına göre daha yüksek olmuştur.
\end{abstract}

Anahtar Kelimeler: Titanyum, kaynak, mikroyapı, sertlik, korozyon

\section{Investigation of Microstructure, Hardness and Acidic Corrosion Properties of TIG Welded Ti6Al4V Titanium Alloy}

\begin{abstract}
Titanium alloys are used in many areas due to their superior properties. Welding can be done in the manufacturing processes made of these alloys or afterwards. In this study, microstructure, hardness and acidic corrosion properties of Ti6Al4V titanium alloy joined by welding were investigated. Since the titanium alloys parts can be used in chemical, petrochemical and similar fields in acidic environments, the corrosion properties have been examined in acidic environment. In the study Ti6Al4V titanium alloy parts were joined by Tungsten Inert Gas (TIG) welding method. The microstructures were examined by optical microscope, and hardness tests were performed using the Vickers method. Electrochemical corrosion experiments were performed by using potentiodynamic method to determine the corrosion behavior in acidic environment. According to the results of the microstructure, it was observed that a good combination was achieved between Ti6Al4V titanium alloy parts by TIG welding and the weld metal consisted of both thin and long morphology $\alpha$ phase grains and very large sized $\beta$ phase grains. The hardness increased in the heat affected zone and weld metal than base metal. The corrosion rate of TIG welded titanium alloy in acidic environment was higher than the unwelded titanium alloy.
\end{abstract}

Keywords: Titanium, welding, microstructure, hardness, corrosion 


\section{GIRIS}

Titanyum ve alaşımları düşük yoğunluk, yüksek mekanik dayanım, çok iyi özgül dayanım, düşük termal genleşme gibi üstün özelliklere sahip metalik malzemelerdir. Bu özelliklere ilave olarak, farklı çevresel ortamlarda titanyum ve alaşımları, yüzeylerinde oluşan oksit filmi sayesinde çok iyi pasifleşmekte ve korozyona karşı çok iyi direnç göstermektedir. Ayrıca titanyum ve alaşımlarının insan vücudu içerisinde bu üstün özelliklerini koruyabilmesi yani biyouyumluluk özelliği de diğer bir avantajlı özelliktir. Bu avantajlı özellikleri nedeniyle titanyum ve alaşımları, havacılık, otomotiv, denizcilik, nükleer, petrokimya ve sağlık alanlarında yaygın şekilde kullanılmaktadır. Bu üstün özelliklerden dolayı titanyum alaşımlarının kullanım alanları ve kullanım oranları da sürekli olarak artış göstermektedir [1$8]$.

Titanyum alaşımlarından yapılacak olan imalatlarda veya imalat sonrası tamir işlemlerinde kaynaklı imalat önemli yer tutmaktadır. Titanyumun kendine özgü özellikleri nedeni ile kaynak işleminde zorluklar çıkmakta, bu zorlukları aşmak için bazı tedbirlerin alınması, uygun kaynak parametrelerinin belirlenmesi gerekmektedir. Kaynak ile birleştirilecek titanyum alaşımına göre uygun kaynak yönteminin seçimi, uygun elektrot ve ilave metal seçimi, kaynak bölgesi temizliği ve koruyucu gaz kullanımı alınacak tedbirlerden en önemli olanlarıdır. Titanyum ve alaşımlarının kaynak işlemini zorlaştıran en önemli faktör, titanyumun oksijene olan afinitesidir. Yüksek oksijen afinitesi sonucunda titanyum yüzeyinde hızlı bir şekilde oksit filmi oluşmaktadır. Kaynaklı imalat esnasında ortaya çıkan yüksek sıcaklıklarda oksit filmi oluşumu çok daha hızlı olmaktadır. Oluşan oksit filminin özellikleri titanyumdan farklı olduğu için kaynak işleminde süreklilik zorlaşmakta, hem oksit parçacıkları hem de havadan kaynak havuzuna giren azot, hidrojen gibi gazlar kaynak metaline geçebilmektedir. Bu geçişler kaynak metalinin mekanik dayanımının azalmasına, kırılganlıklara ve sonuç olarak kötü bir kaynaklı birleştirmeye neden olmaktadır [1, 5, 6, 8-10]. Titanyum alaşımlarının kaynaklı birleştirme işlemlerinde lazer 1şını kaynağı, lazer hibrit kaynağı, elektron 1şın kaynağ1, sürtünme kaynağ yöntemleri kullanılmakla birlikte TIG kaynak yöntemi tercih edilen bir yöntemdir [1, 2, 9, 11]. TIG kaynak yönteminin tercih edilmesinde, düşük maliyet, yöntemin basitliği, otomasyona uygunluk en önemli etkenlerdir [3, 12-14].

Kimyasal bileşim ve üretim şartlarına bağlı olarak oluşan mikroyapı titanyum alaşımlarının özelliklerinin oluşmasında temel faktördür. Sertlik, dayanım gibi mekanik özellikler ve korozyon gibi elektrokimyasal özellikler, titanyum alaşımlarının mikroyapısından ve üretimde veya üretim sonrası uygulanan 1 sıl işlemlerden etkilenmektedir. Titanyum ve alaşımlarının kaynaklı birleştirme işlemlerinde ortaya çıkan yüksek sıcaklıklar, kaynak bölgesinin mikroyapısını esas metale göre oldukça farklılaştırmaktadır. Bu yüksek sıcaklıklar sebebi ile kaynak metali kimyasal bileşiminde ve mikroyapısında lokal olarak homojensizlikler oluşabilmektedir. Kaynak metali olarak adlandırılan ergime bölgesinde ve kaynak metali yanındaki ergime olmayan ısıdan etkilenen bölgede mikroyapısal olarak tane büyümesi olmaktadır. Esas metal ve kaynak bölgesinin farklı mikroyapılarda olması titanyum alaşımlarının korozyon özelliğine etki edebilmektedir [15-18].

Titanyum ve alaşımlarının farklı asidik ortamlardaki korozyon davranışları ile ilgili çeşitli çalışmalar bulunmaktadır [19-28]. Bu çalışmalarda ticari saflıkta titanyum ve farklı titanyum alaşımlarının nitrik asit, sülfürik asit, okzalik asit, laktik asit, kromik asit, formik asit, fosforik asit gibi çözelti ortamlarında korozyon davranışları incelenmiştir. Atmosferik ve tuzlu ortamlarda titanyuma iyi bir korozyon dayanımı sağlayan yüzeyde oluşan pasif oksit filminin, asidik ortamlarda da benzer davranışı gösterdiği yapılan çalışmaların sonuçlarında bildirilmektedir. Kaynak ile birleştirilmiş titanyumun korozyon davranışının incelendiği az sayıda çalışma vardır. İki farklı çalışmada $[13,15]$ kaynak ile birleştirilmiş titanyumun lityum bromür çözeltisindeki korozyon davranışı incelenmiş, kaynak işlemi ile mikroyapının büyük ölçüde değiştiği, malzeme bileşiminde bölgesel farklılıklar oluştuğu ve bu değişimlerin korozyon dayanımını azalttığı belirtilmiştir. Tuzlu su ortamında korozyon davranışının incelendiği başka çalışmalarda da $[14,16]$ titanyum alaşımının ergitmeli yöntemler ile kaynaklı birleştirmesinde kaynak metalinin oldukça büyük boyutlu kolonsal tanelerden oluştuğu, bu yapının korozyon dayanımını olumsuz etkilediği bildirilmiştir. 
Saf titanyum ve titanyum alaşımlarının mikroyapı, mekanik ve korozyon özellikleri hakkında çeşitli çalışmalar bulunmaktadır. Kaynak ile birleştirilen titanyumun mikroyapı ve mekanik özellikleri ile ilgili çalışmalar da mevcuttur. Fakat kaynak ile birleştirilmiş titanyum alaşımlarının korozyon davranışları ile ilgili özellikle de asidik ortamlardaki korozyon davranışları ile ilgili çalışma çok az sayıdadır. Halbuki kaynaklı birleştirme ile imal edilen titanyum alaşımı parçalar çeşitli kimya, petrokimya ve benzeri endüstriyel alanlarda asidik ortamlarda kullanılmaktadır. Dolayısı ile kaynaklı titanyum alaşımlarının asidik korozyon davranışının belirlenmesi önemlidir. Bu çalışmada TIG kaynağı ile birleştirilen Ti6Al4V titanyum alaşımının asidik ortamdaki korozyon özellikleri incelenmiş, kaynak işleminin asidik korozyon davranışına etkileri belirlenmiştir. Bunun yanında malzeme özelliklerinde önemli etkisi olan mikroyapı ve malzemelerin mekanik davranışları hakkında genel bilgi veren sertlik özellikleri de incelenmiştir.

\section{DENEYSEL CALISSMALAR}

TIG kaynak yöntemi ile yapılan birleştirmelerde Tablo 1'de kimyasal bileşimi verilen Ti6A14V titanyum alaşımı kullanılmıştır. Titanyum alaşımının kalınlığ $2 \mathrm{~mm}$ olup, parçaların ince olması nedeniyle kaynak ağzı açılmadan birleştirme yapılmıştır. TIG kaynağı işlemi, argon koruyucu gaz atmosferinde, $2.4 \mathrm{~mm}$ çapında tungsten elektrot, $1.5 \mathrm{~mm}$ çapında AMS4954 ilave kaynak teli ve 75 amper akım kullanılarak 200 mm/dak kaynak hızında yapılmışır.

Tablo 1. Titanyum alaşımının kimyasal bileşimi (A

\begin{tabular}{ccccc}
\hline Al & $\mathbf{V}$ & $\mathbf{F e}$ & $\mathbf{C}$ & $\mathbf{T i}$ \\
\hline 6 & 4 & 0.25 & 0.08 & Kalan \\
\hline
\end{tabular}

Kaynak işlemi sonrası mikroyapı ve sertlik incelemeleri için $20 \times 20 \mathrm{~mm}$ ölçüsünde kesilen $2 \mathrm{~mm}$ kalınlığındaki kaynaklı parçalara sıcak kalıplama, zımparalama ve parlatma metalografik hazırlık işlemleri uygulanmıştır. Parlatılan numunelerin dağlanmasında Kroll reaktifi $(2 \mathrm{ml} \mathrm{HF}+4 \mathrm{ml} \mathrm{HNO}+100$ $\mathrm{ml} \mathrm{H}_{2} \mathrm{O}$ ) kullanılmıştır. Mikroyapı görüntüleri Nikon Eclipse LV150N optik mikroskop ile incelenerek, esas metal, 1sıdan etkilenen bölge ve kaynak metali (dikişi) mikroyapı görüntüleri alınmıştır.

TIG kaynağı ile birleştirilen Ti6Al4V titanyum alaşımında sertlik değişimini belirlemek için esas metal ve yanındaki kaynak bölgelerinden (ITAB ve kaynak metali) sertlik ölçümleri yapılmıştır. Sertlik testlerinde Metkon Duroline sertlik ölçme cihazı kullanılmıştır. Vickers yöntemine göre sertlik ölçümünde 30 saniye süresince $1 \mathrm{~kg}$ yük uygulanarak sertlik değişimi belirlenmiştir.

TIG kaynağı ile birleştirilen Ti6Al4V titanyum alaşımının ve kaynaksız alaşımın asidik ortamdaki korozyon davranışlarının incelenmesi için ayrı ayrı 25×80 mm ölçüsünde kesilen $2 \mathrm{~mm}$ kalınlığındaki parçalardan $2 \times 25 \mathrm{~mm}$ ölçüsünde yüzey açıkta kalacak şekilde soğuk kalıplama yöntemi ile elektrokimyasal incelemelerde kullanılacak çalışma elektrotları hazırlanmıştır. Elektrokimyasal çalışmalarda asidik ortam olarak $1 \mathrm{M} \mathrm{HCl} \mathrm{çözeltisi,} \mathrm{karşı} \mathrm{elektrot} \mathrm{olarak} \mathrm{platin,} \mathrm{referans} \mathrm{elektrot} \mathrm{olarak}$ doygun kalomel elektrot kullanılmıştır. Ivium marka potansiyostat cihazı ile yapılan korozyon çalışmalarında potansiyodinamik yöntem ile polarizasyon ve Tafel polarizasyon eğrileri elde edilmiştir. Tafel polarizasyon eğrilerinden korozyon potansiyeli, korozyon akımı ve korozyon hızı belirlenmiştir.

\section{SONUCLAR VE TARTIȘMA}

\section{A. MIKROYAPISAL INCELEME SONUÇLARI}

Optik mikroskop ile yapılan metalografik incelemeler sonucunda, kaynak bölgelerine göre elde edilen mikroyapı görüntüleri Şekil 1-3'de verilmektedir. Bu görüntülerde esas metal, 1sı tesiri altındaki bölge ve kaynak metali mikroyapıları görülmektedir. Şekil 1'deki mikroyapı görüntülerinde, haddeleme ile imal edilmiş olan Ti6Al4V titanyum alaşımı malzemede kaynak ısısından etkilenmeyen esas metalin 
oldukça küçük boyutlu eşeksenel tanelerden oluştuğu görülmektedir. Ti6Al4V titanyum alaşımı başlangıçta orijinal alfa $(\alpha)$ ve beta $(\beta)$ fazlarından oluşmaktadır.

Esas metalin hemen yanında yeniden kristalleşme sonucu oluşan küçük tane yapısına sahip 1sı tesiri altındaki kaynak bölgesi bulunmaktadır. Bu bölgenin tane boyutu esas metal tane boyutundan biraz daha büyüktür. Bu bölgenin yanında kaynak metaline yakın olan ve yüksek 1sı nedeniyle tane irileşmesinin olduğu büyük tane yapısına sahip 1sı tesiri altındaki bölge mevcuttur. Bu bölgedeki büyük boyutlu taneler $\beta$ fazı olup ortalama $300 \mu \mathrm{m}$ tane boyutundadır. İnce uzun morfolojideki asiküler yapıdaki $\alpha$ fazı taneleri az miktarda da olsa mevcuttur.

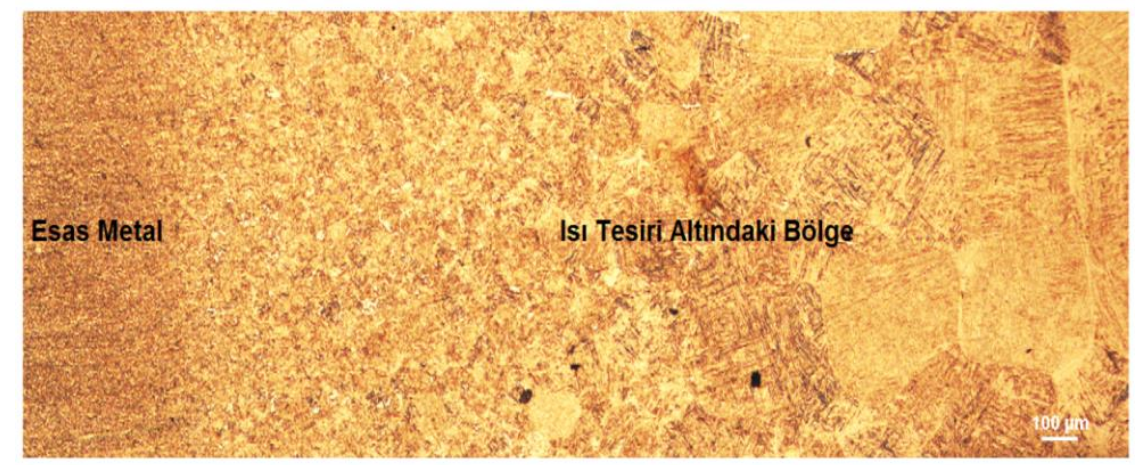

Şekil 1. Esas metal ve tsı tesiri altındaki bölge mikroyapısl

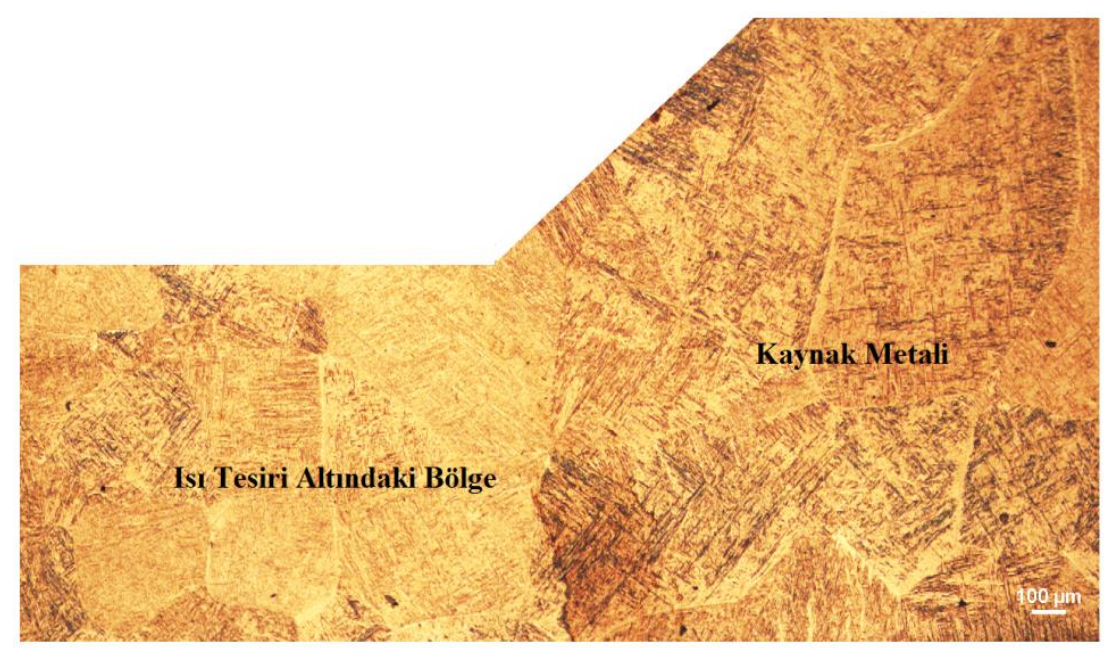

Şekil 2. Ist tesiri altındaki bölge ve kaynak metali mikroyapısl

Şekil 2'de büyük tane boyutlu 1sı tesiri altındaki bölge ve kaynak metali birlikte görülmektedir. Ti6A14V alaşımının TIG yöntemi ile yapılan kaynak işleminde iyi bir birleşmenin olduğu, kaynak metali ile 1sı tesiri altındaki bölge ara yüzeyinde herhangi bir boşluk, çatlak gibi hataların olmadığı görülmektedir. Kaynak metali, kaynak dikişi olup ısının en yüksek seviyelere ulaştığı, kaynak işlemi sırasında ergime ve devamında tekrar katılaşmanın olduğu bölgedir. Bu bölgede tane yapıs1 1sı tesiri altındaki tanelere göre çok daha büyük boyutlu $\beta$ fazı tanelerinden ve ince uzun morfolojide asiküler $\alpha$ fazı tanelerinden oluşmaktadır. Esas metalden kaynak metaline doğru ilerledikçe alaşımın tane yapısının kaynak ısısı etkisiyle sürekli olarak büyüdüğ̈̈ görülmektedir. Büyük boyutlu $\beta$ fazı taneleri içerisinde bulunan asiküler $\alpha$ fazı taneleri kaynak metalinin hızlı soğuması sonucu oluşan bir yapı olup bu faz bazı çalışmalarda $\alpha^{\prime}$ martenzit olarak da adlandırılmaktadır $[2,12,14]$. Titanyumun örtülü elektrot, TIG, MIG gibi ergitmeli kaynak yöntemleri ile birleştirilmesinde kaynak metali büyük boyutlu $\beta$ fazı taneleri ile karakterize edilmektedir. Bazı çalışmalarda kaynak metalini oluşturan büyük boyutlu $\beta$ fazı tanelerinin kaynak işleminde ortaya çıkan termal koşullar nedeniyle oluştuğu bildirilmektedir. Büyük tane 
boyutuna sahip $\beta$ fazı taneleri, kaynak ısısının soğuma yönünde uzayan kolonsal taneler olup, bu yapının kaynak metalinin mekanik özelliklerini olumsuz yönde etkilediği belirtilmektedir $[14,16]$.

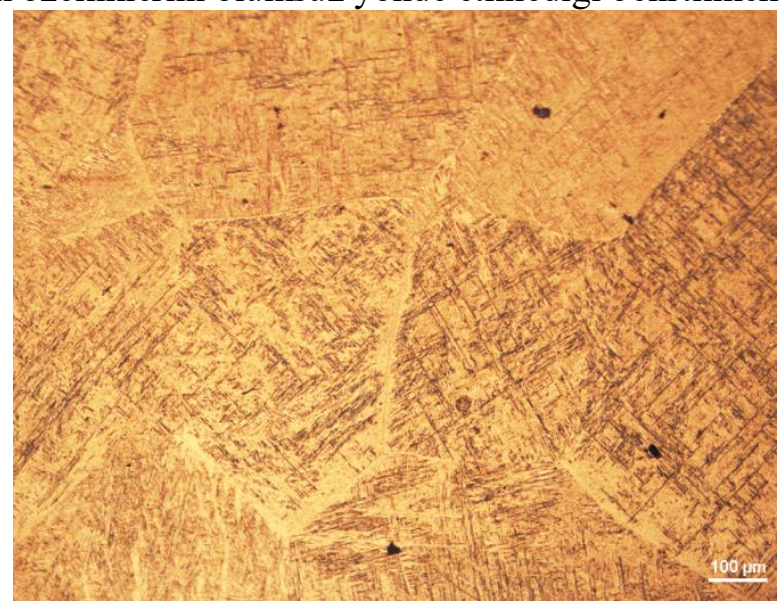

Şekil 3. Kaynak metali mikroyapısı

Şekil 3'de kaynak metali mikroyapısı verilmektedir. Büyük tane boyutlu $\beta$ fazı yapısı ve farklı yönlenmelerdeki asiküler $\alpha$ fazı yapısı bu mikroyapıda daha iyi görünmektedir. Ti6Al4V alaşımının kullanıldığı bazı çalışmalarda $[2,14]$ asiküler $\alpha$ fazının ilk olarak $\beta$ fazı sınırlarında çekirdeklenmeye başladığı, $\beta$ fazı içerisine doğru büyüdüğü, benzer şekilde büyüyen diğer asiküler $\alpha$ fazına temas edene kadar büyümenin paralel plakalar şeklinde devam ettiği belirtilmektedir. Soğuma hızı arttıkça asiküler $\alpha$ taneleri daha ince bir morfolojide oluşmaktadır.

\section{B. SERTLIKK INCELEME SONUÇLARI}

Esas metal, ısı tesiri altındaki bölge ve kaynak metali sertlik ölçüm sonuçlarına göre Ti6Al4V alaşımının sertlik değişimi Şekil 4'te verilmektedir. Sertlik grafiğine göre, esas metal sertlik değeri yaklaşı 350 HV değerinde iken, ısıdan etkilenen bölge sertliği 364-402 HV aralığında ve kaynak metali sertliği 380390 HV seviyelerindedir.

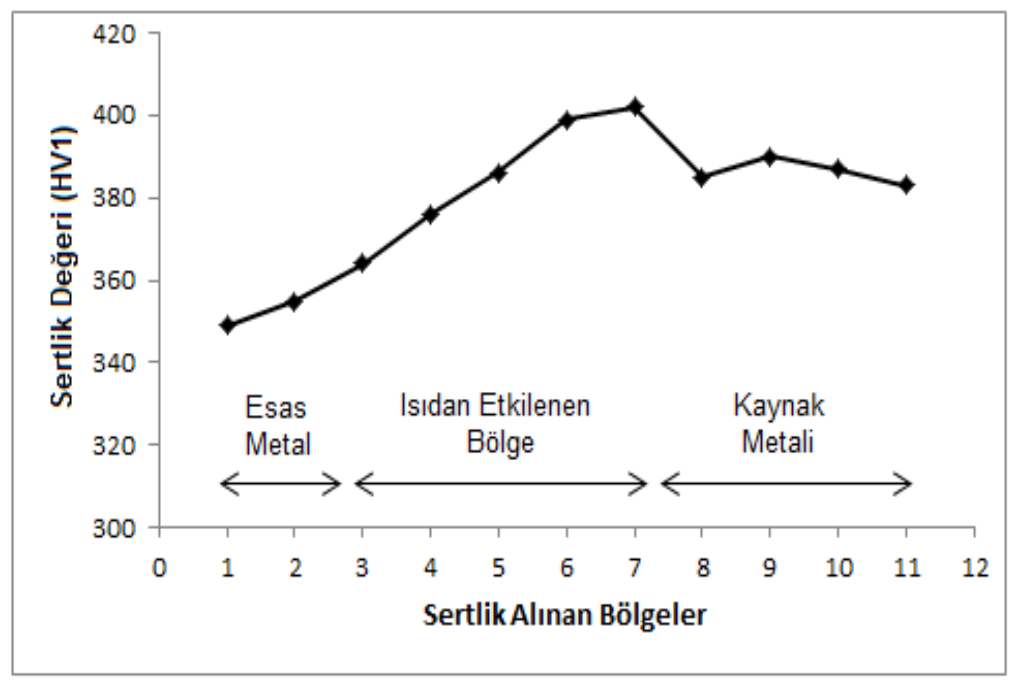

Şekil 4. Kaynak bölgelerine göre sertlik değişimi

TIG kaynak yöntemi ile birleştirilen Ti6Al4V titanyum alaşımında esas metalden kaynak metaline doğru ilerledikçe sertlikte sürekli bir değişim olduğu görülmektedir. Kaynak metaline kadar 1sı tesiri altındaki bölge sertliği sürekli artmaktadır. Kaynak metalinde ise sertlik değerlerinde bir miktar azalma olmuştur. $\mathrm{Bu}$ şekilde sertlik değişiminin en önemli nedeni, kaynak işlemi ile birlikte titanyum alaşımında 
mikroyapısal bir farklılığın oluşmasıdır. Grafiğe göre malzeme sertliğinin en düşük olduğu bölge esas metaldir. Bu bölge, haddeleme ile üretilmiş olan malzemede orijinal $\alpha$ fazı ve $\beta$ fazından oluşmakta olup, bu bölgede kaynak sırasında ortaya çıkan isıdan yapısal olarak etkilenme olmamaktadır. $\mathrm{Bu}$ nedenle en düşük sertlik değeri esas metalde elde edilmiştir. Esas metalden 1sının tesiri altındaki bölgeye geçildiğinde sertlik değerinde sürekli artış olduğu görülmektedir. Sertlik değerleri kaynak metaline yaklaşıldıkça artmaktadır. Isı tesiri altındaki bölgenin başlangıcında sertlik değeri $364 \mathrm{HV}$ iken kaynak metali sınırında sertlik değeri $402 \mathrm{HV}$ seviyelerindedir. Bu bölge ergimenin olmadı̆̆ 1 fakat yüksek sıcaklıklara ulaşılan kaynak bölgesidir. Özellikle kaynak metaline bitişik sınır bölgeleri alaşımın katı durumda bulunduğu en yüksek sıcaklık bölgesidir. Yüksek sıcaklıklardan hızlı soğuma sonucu oluşan çok ince yapıdaki asiküler $\alpha$ fazı bu bölgede bulunmaktadır. Bu nedenlerden dolayı sertlik değerleri bu bölgede yüksektir. Kaynak metalinde ise sertlik biraz azalmakla birlikte esas metale göre yüksek seviyelerdedir. Kaynak metali, kaynak sırasında sıcaklığın en yüksek seviyelere ulaştığı, ergime ve sonrasında soğuma sonucu bölgesel katılaşmanın olduğu bölge olup, mikroyapı olarak ince yapıdaki asiküler $\alpha$ fazının en fazla olduğu bölgedir. Sonuçta esas metalden kaynak metaline doğru sertlik artışında yapıda bulunan asiküler $\alpha$ fazı temel etkenlerdendir. Ticari saflıktaki alüminyum ve titanyum alaşımlarının TIG kaynağı ile ilgili çalışmalarda da [6,9] sertlik değişimi benzer şekilde bulunmuş, ısıdan etkilenen bölge ve kaynak metalinde en yüksek sertlik değerleri elde edilmiştir. Bu çalışmalarda, ısıdan etkilenen bölge ve kaynak metali mikroyapısında bulunan çok büyük boyutlu $\beta$ fazı tanelerinin sertlik özelliğinde etkili olmadığ belirtilmiştir. Kaynak sonrası hızlı soğuma ile oluşan çok ince tane yapısındaki asiküler $\alpha$ fazının malzemede sertlik artışının temel nedeni olduğu bildirilmiştir. Ayrıca kaynak 1sı girdisinin azalması ile kaynak metali sertliğinin arttığı da belirlenmiştir.

\section{ELEKTROKIMYYSAL INCELEME SONUÇLARI}

Kaynaksız ve kaynaklı Ti6A14V titanyum alaşımının asidik ortamdaki elektrokimyasal incelemelerinde elde edilen polarizasyon eğrileri Şekil 5 ve Şekil 6'da, Tafel polarizasyon eğrileri Şekil 7'de, bazı sayısal korozyon sonuçları Tablo 2'de verilmektedir.

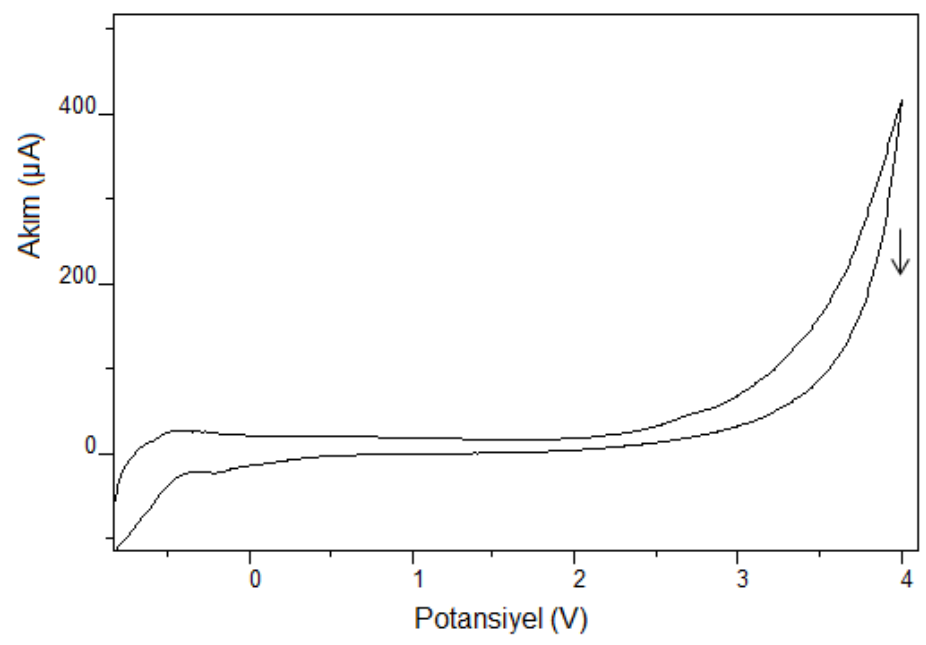

Şekil 5. Kaynaksız Ti6Al4V titanyum alaşımının polarizasyon eğrisi 


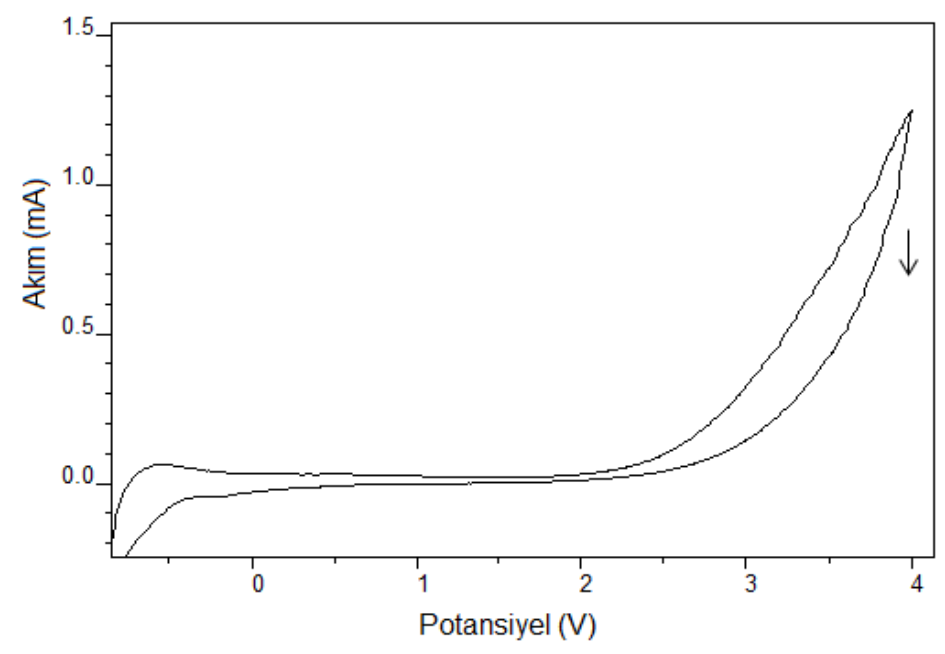

Şekil 6. Kaynaklı Ti6Al4V titanyum alaşımının polarizasyon ĕgrisi

Asidik ortamda yapılan elektrokimyasal çalışmalarda, kaynaksız ve kaynaklı Ti6Al4V titanyum alaşımlarına, $1 \mathrm{M} \mathrm{HCl}$ çözeltisinde $-1.5 \mathrm{~V}$ ile $4 \mathrm{~V}$ arasında potansiyel uygulanarak alaşımdan geçen akım değişimi takip edilmiştir. Korozyonun olmayacağı çok düşük seviyelerdeki potansiyel, daha yüksek seviyelere çıkarılmış, bu şartlarda dahi akım artı̧̧ çok düşük seviyelerde olmuştur. Uygulanan geniş bir potansiyel aralığında akım sıfır seviyesinde devam etmiştir. Bu pasif davranışını sağlayan, titanyum alaşımı yüzeyinde oluşan kararlı titanyum oksit filmidir. $\mathrm{Bu}$ film genellikle $\mathrm{TiO}_{2}$ esaslı bir film olup, titanyum ile çevresel ortam arasında bariyer etkisi yaparak pasifleşmeyi sağlamaktadır [21, 23, 25, 28]. Kaynaksız titanyum alaşımında yaklaşık $2 \mathrm{~V}$ potansiyel değerinde akım artışı başlarken, kaynaklı titanyum alaşımında ise daha erken şekilde yaklaşık $1.5 \mathrm{~V}$ gibi daha düşük potansiyel değerinde akım artışı başlamaktadır. Kaynaklı titanyum alaşımında daha düşük potansiyel değerinde pasifliğin bozulması yapılan kaynak işleminin elektrokimyasal dayanımı olumsuz etkilediğini göstermektedir. Uygulanan en yüksek potansiyel değerinde kaynaklı titanyum alaşımından geçen akım değeri, kaynaksız titanyum alaşımına göre biraz daha yüksek olmuştur. Kaynaksız titanyum alaşımında $4 \mathrm{~V}$ potansiyel uygulandığında akım değeri yaklaşık $400 \mu \mathrm{A}$ iken, aynı potansiyel değerinde kaynaklı titanyum alaşımından geçen akım değeri $1.3 \mathrm{~mA}$ seviyelerindedir. Polarizasyon eğrilerinde ok ile gösterildiği gibi dönüş eğrisi alttaki eğridir. Bu da yüzeyde elektrokimyasal bozulmanın olmadığına işaret etmektedir.

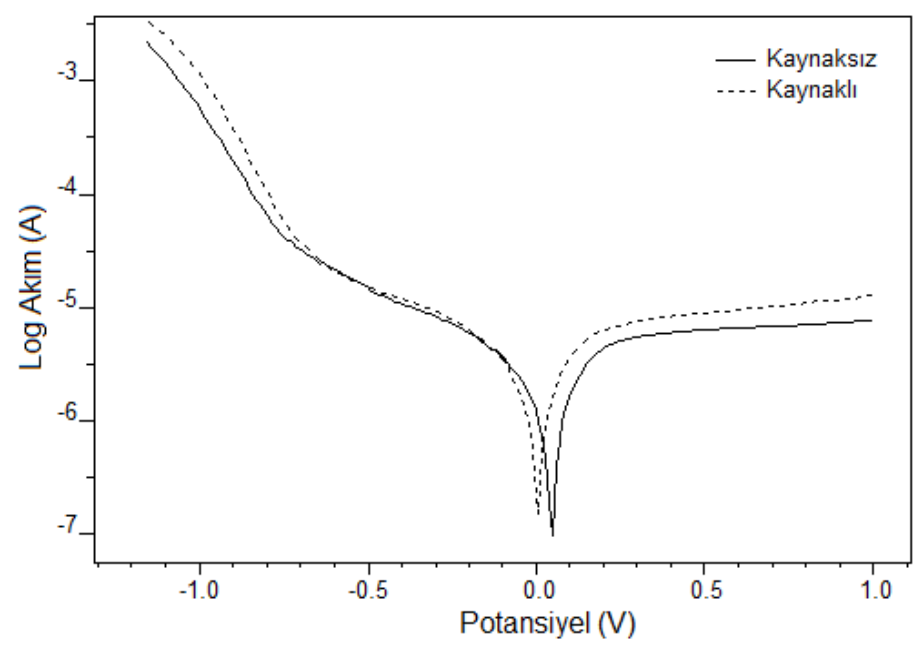

Şekil 7. Kaynaksız ve kaynaklı Ti6Al4V titanyum alaşımının Tafel polarizasyon eğrileri 
Tablo 2. Kaynaksız ve kaynaklı Ti6Al4V titanyum alaşımının korozyon verileri

\begin{tabular}{lccc}
\hline & $\begin{array}{c}\text { Korozyon Potansiyeli } \\
(\boldsymbol{m} \boldsymbol{V})\end{array}$ & $\begin{array}{c}\text { Korozyon Akımı } \\
\left(\boldsymbol{A} / \mathbf{c m}^{\mathbf{2}}\right)\end{array}$ & $\begin{array}{c}\text { Korozyon Hızı } \\
(\boldsymbol{m m} / \boldsymbol{y})\end{array}$ \\
\hline $\begin{array}{c}\text { Kaynaks1z } \\
\text { Ti6A14V }\end{array}$ & +33 & $5.086 .10^{-6}$ & 0.089 \\
\hline $\begin{array}{l}\text { Kaynakl1 } \\
\text { Ti6A14V }\end{array}$ & -25 & $7.274 .10^{-6}$ & 0.127 \\
\hline
\end{tabular}

Tablo 2'de verilen Tafel polarizasyon eğrilerinden elde edilen elektrokimyasal veriler incelendiğinde, kaynaklı titanyum alaşımının korozyon potansiyelinin negatif yönde değiştiği görülmektedir. Kaynaksız titanyum alaşımında $33 \mathrm{mV}$ olan korozyon potansiyeli değeri, kaynaklı titanyum alaşımında $-25 \mathrm{mV}$ olarak belirlenmiştir. Buna göre kaynak işlemi ile korozyon potansiyeli $58 \mathrm{mV}$ negatif yönde değişmiştir. Korozyon potansiyelinin negatif yönde değişimi elektrokimyasal dayanımın azalmasının göstergesi olabilmektedir. Korozyon akımı ve korozyon hızı değerleri kaynaksız titanyum alaşımına göre kaynaklı titanyum alaşımında artış göstermiştir. Kaynaksız titanyum alaşımında $5.086 .10^{-6} \mathrm{~A} / \mathrm{cm}^{2}$ olan korozyon akım yoğunluğu, kaynaklı titanyum alaşımında $7.274 .10^{-6} \mathrm{~A} / \mathrm{cm}^{2}$ değerine, kaynaksız titanyum alaşımında $0.089 \mathrm{~mm} / \mathrm{y}$ olan korozyon hızı ise kaynaklı titanyum alaşımında $0.127 \mathrm{~mm} / \mathrm{y}$ değerine yükselmiştir. Buna göre bu çalışmada yapılmış olan TIG kaynak işlemi Ti6Al4V titanyum alaşımının korozyon akımını ve bunun sonucunda korozyon hızını artırmaktadır. Zaten elektrokimyasal olarak korozyon akımı ve korozyon hızı birbirleri ile doğru orantılıdır. Metallerde korozyon akımının artması ile korozyon nedeniyle çözünen madde miktarı da artmaktadır. Çözünen madde miktarının artması korozyonun daha hızlı olması demektir. Kaynak işlemi ile Ti6Al4V titanyum alaşımının korozyon hızının artması yani korozyon dayanımının azalmasında kaynaklı birleştirme sonucu ortaya çıkan yapısal değişimin etkili olduğu düşünülmektedir. Kaynaksız titanyum alaşımı küçük tane boyutunda malzemenin her tarafinda homojen bir yapıda orijinal $\alpha$ fazı ve $\beta$ fazından oluşurken, kaynaklı titanyum alaşımı esas metalden farklı olarak homojen olmayan bir tane boyutu ve morfolojisine sahiptir. Kaynaklı titanyum alaşımında esas metalden kaynak metaline doğru sürekli büyüyen tane boyutu ve kaynak sonrası hızlı soğuma sonucu oluşan asiküler $\alpha$ fazı taneleri bulunmaktadır. Kaynaklı titanyum alaşımında bu şekilde homojen olmayan mikroyapının varlığı, korozyon hızını artırıcı, korozyon direncini düşürücü etki yapmaktadır. Darbeli TIG kaynă̆ 1 ile birleştirilen titanyum alaşımının tuzlu su ortamındaki korozyon davranışının incelendiği çalışmalarda $[14,16]$, yüksek değerlerdeki kaynak sıcaklığı sonucu oluşan çok büyük tane boyutuna sahip $\beta$ fazının titanyum alaşımının korozyon direncini olumsuz yönde etkilediği bildirilmiştir. Kaynak ile birleştirilmiş ticari saflıkta titanyumun lityum bromür çözeltisindeki korozyon özelliklerinin incelendiği başka iki çalışmada da [13, 15], eşeksenli ve küçük boyutlu $\alpha$ fazı ile $\beta$ fazından oluşan saf titanyumun kaynak işlemi sonrasında $\alpha$ fazının plakalı yapıdaki widmanstatten $\alpha$ fazına dönüştüğü ve bu yapının titanyumun korozyon davranışını olumsuz etkilediği bildirilmiştir. Bu çalışmalarda da kaynaksız saf titanyuma göre kaynaklı saf titanyumun korozyon potansiyelinin negatif yönde değiştiği, korozyon akımının ve korozyon hızının arttığı belirlenmiştir.

\section{CIKARIMLAR}

TIG kaynağ1 ile birleştirilen Ti6Al4V titanyum alaşımı malzemenin mikroyapı, sertlik ve asidik ortamdaki korozyon özelliklerinin incelendiği bu çalışmada aşağıdaki çıkarımlar elde edilmiştir:

- Mikroyapısal incelemelere göre Ti6Al4V titanyum alaşımının TIG kaynağı ile birleştirilmesi, esas metal ve kaynak metali ara yüzeyinde boşluk, çatlak ve benzeri hatalar olmayacak şekilde elde edilmiştir.

- Esas metalden kaynak metaline doğru tane boyutu sürekli artmıştır. En büyük tane boyutu kaynak metalinde $\beta$ fazı olarak görülmüştür. Kaynak metalinde, kaynak sonrası hızlı soğuma 
sonucunda oluşan ince uzun morfolojide asiküler $\alpha$ fazı taneleri bulunmaktadır. Asiküler $\alpha$ fazı, kaynak metali yanında bulunan 1sı tesiri altındaki bölgede düşük oranlarda mevcuttur.

- Esas metale göre 1 sıdan etkilenen bölge ve kaynak metali sertliği daha yüksek olmuştur. Bu sertlik artışında hızlı soğuma sonucu oluşan ince uzun paralel plakalar şeklindeki asiküler $\alpha$ fazı etkili olmaktadır.

- Ti6Al4V titanyum alaşımının TIG kaynaklı birleştirme işlemi sonucunda elektrokimyasal özelliklerde değişim olmuştur. Kaynaklı titanyum alaşımında korozyon akımı ve korozyon hızı artmış, korozyon potansiyeli negatif yönde değişmiştir. Buna göre kaynak işlemi ile Ti6Al4V alaşımının korozyon dayanımında azalma olmuştur. Bu olumsuz değişimde kaynak sonucu oluşan homojen olmayan mikroyapı etkili olmaktadır.

- Bu çalışmada uygulanan TIG kaynak işleminde kaynak parametreleri sabit tutulmuştur. Başka çalışmalarda farklı kaynak parametreleri kullanılarak bu parametrelerin mikroyapı, sertlik ve korozyon davranışına etkileri incelenebilir. Ayrıca, Ti6A14V titanyum alaşımı farklı kaynak yöntemleri ile birleştirilerek, elde edilen özellikler karşılaştırılabilir.

\section{KAYNAKLAR}

[1] Q. Yunlian, D. Ju, H. Quan, Z. Liying, "Electron Beam Welding, Laser Beam Welding and Gas Tungsten Arc Welding of Titanium Sheet," Mater. Sci. Eng. A, c. 280, ss. 177-181, 2000.

[2] Z. Xu, Z. Dong, Z. Yu, W. Wang, J. Zhang, "Relationships Between Microhardness, Microstructure, and Grain Orientation in Laser-Welded Joints with Different Welding Speeds for Ti6Al4V Titanium Alloy", Trans. Nonferrous Met. Soc. China, c. 30, ss. 1277-1289, 2020.

[3] C. Xu, G. Sheng, H. Feng, X. Yuan, "Tungsten Inert Gas Welding Brazing of AZ31B Magnesium Alloy to TC4 Titanium Alloy”, J. Mater. Sci. Technol., c. 32, ss. 167-171, 2016.

[4] Y. Zhang, J. Huang, Z. Ye, Z. Cheng, "An Investigation on Butt Joints of Ti6Al4V and 5A06 Using MIG/TIG Double-Side Arc Welding-Brazing”, J. Manuf. Process., c. 27, ss. 221-225, 2017.

[5] R. Bendikiene, S. Baskutis, J. Baskutiene, A. Ciuplys, T. Kacinskas, "Comparative Study of TIG Welded Commercially Pure Titanium”, J. Manuf. Process., c. 36, ss. 155-163, 2018.

[6] A. Karpagaraj, N.S. Shanmugam, K. Sankaranarayanasamy, "Some Studies on Mechanical Properties and Microstructural Characterization of Automated TIG Welding of Thin Commercially Pure Titanium Sheets", Mater. Sci. Eng. A, c. 640, ss. 180-189, 2015.

[7] L. Shixiong, Q. Cui, Y. Huang, X. Jing, "Influence of Zr Addition on TIG Welding-Brazing of Ti-6Al-4V to Al5A06", Mater. Sci. Eng. A, c. 568, ss. 150-154, 2013.

[8] B.H. Choi, B.K. Choi, "The Effect of Welding Conditions According to Mechanical Properties of Pure Titanium", J. Mater. Process. Technol., c. 201, ss. 526-530, 2008.

[9] M. Junaid, M.N. Baig, M. Shamir, F.N. Khan, K. Rehman, J. Haider, "A Comparative Study of Pulsed Laser and Pulsed TIG Welding of Ti-5Al-2.5Sn Titanium Alloy Sheet", J. Mater. Process. Technol., c. 242, ss. 24-38, 2017.

[10] Q. Chu, M. Zhang, J. Li, C. Yan, Z. Qin, "Influence of Vanadium Filler on the Properties of Titanium and Steel TIG Welded Joints", J. Mater. Process. Technol., c. 240, ss. 293-304, 2017.

[11] X.L. Gao, L.J. Zhang, J. Liu, J.X. Zhang, "A Comparative Study of Pulsed Nd:YAG Laser Welding and TIG Welding of Thin Ti6Al4V Titanium Alloy Plate", Mater. Sci. Eng. A, c. 559, ss. 14$21,2013$. 
[12] J. Xiong, S. Li, F. Gao, J. Zhang, "Microstructure and Mechanical Properties of Ti6321 Alloy Welded Joint by GTAW", Mater. Sci. Eng. A, c. 640, ss. 419-423, 2015.

[13] E.B. Tamarit, A.I. Munoz, J.G. Anton, D.G. Garcia, "Corrosion Behaviour and Galvanic Coupling of Titanium and Welded Titanium in Libr Solutions", Corros. Sci., c. 49, ss. 1000-1026, 2007.

[14] M. Balasubramanian, V. Jayabalan, V. Balasubramanian, "Effect of Pulsed Gas Tungsten Arc Welding on Corrosion Behavior of Ti-6Al-4V Titanium Alloy", Mater. Design, c. 29, ss. 1359-1363, 2008.

[15] E.B. Tamarit, A.I. Munoz, J.G. Anton, D.M. Garcia, "Galvanic Corrosion of Titanium Coupled to Welded Titanium in Libr Solutions at Different Temperatures", Corros. Sci., c. 51, ss. 1095-1102, 2009.

[16] M. Balasubramanian, V. Jayabalan, V. Balaubramanian, "Modeling Corrosion Behavior of Gas Tungsten Arc Welded Titanium Alloy", Trans. Nonferrous Met. Soc. China, c. 17, ss. 676-680, 2007.

[17] P. Ferro, F. Berto, F. Bonollo, L. Romanin, G. Salemi, "Post Welding Heat Treatment Improving Mechanical Properties on Ti-6Al-4V”, Procedia Struct. Integrity, c. 26, ss. 11-19, 2020.

[18] J. Shi, G. Song, J. Chi, "Effect of Active Gas on Weld Appearance and Performance in LaserTIG Hybrid Welded Titanium Alloy”, Int. J. Lightweight Mater. Manuf., c. 1, ss. 47-53, 2018.

[19] Z.B. Wang, H.X. Hu, Y.G. Zheng, W. Ke, Y.X. Qiao, "Comparison of the Corrosion Behavior of Pure Titanium and Its Alloys in Fluoride-Containing Sulfuric Acid", Corros. Sci., c. 103, ss. 50-65, 2016.

[20] S. Ningshen, M. Sakairi, K. Suzuki, T. Okuno, "Corrosion Performance and Surface Analysis of Ti-Ni-Pd-Ru-Cr Alloy in Nitric Acid Solution”, Corros. Sci., c. 91, ss. 120-128, 2015.

[21] A. Robin, H.R.Z. Sandim, J. Rosa, "Corrosion Behavior of the Ti-\%4Al-\%4V Alloy in Boiling Nitric Acid Solutions", Corros. Sci., c. 41, ss. 1333-1346, 1999.

[22] A.M. Fekry, "The Influence of Chloride and Sulphate Ions on the Corrosion Behavior of Ti and Ti-6Al-4V Alloy in Oxalic Acid", Electrochim. Acta, c. 54, ss. 3480-3489, 2009.

[23] Z.B. Wang, H.X. Hua, C.B. Liu, Y.G. Zheng, "The Effect of Fluoride Ions on the Corrosion Behavior of Pure Titanium in 0.05 M Sulfuric Acid”, Electrochim. Acta, c. 135, ss. 526-535, 2014.

[24] M. Koike, H. Fujii, "The Corrosion Resistance of Pure Titanium in Organic Acids", Biomater., c. 22, ss. 2931-2936, 2001.

[25] Z. Jiang, X. Dai, H. Middleton, "Investigation on Passivity of Titanium under Steady-State Conditions in Acidic Solutions", Mater. Chem. Phys., c. 126, ss. 859-865, 2011.

[26] I. Gurrappa, D.V. Reddy, "Characterisation of Titanium Alloy, IMI-834 for Corrosion Resistance under Different Environmental Conditions", J. Alloy Compd., c. 390, ss. 270-274, 2005.

[27] J.S. Lu, "Corrosion of Titanium in Phosphoric Acid at $250{ }^{\circ} \mathrm{C}$ ", Trans. Nonferrous Met. Soc. China, c. 19, ss. 552-556, 2009.

[28] G. Mabilleau, S. Bourdon, M.L.J. Guillou, R. Filmon, M.F. Basle, D. Chappard, "Influence of Fluoride, Hydrogen Peroxide and Lactic Acid on the Corrosion Resistance of Commercially Pure Titanium, Acta Biomater., c. 2, ss. 121-129, 2006. 